Article

\title{
Foraging Behavior and Pollination Efficiency of Apis mellifera L. on the Oil Tree Peony 'Feng Dan' (Paeonia ostii T. Hong et J.X. Zhang)
}

\author{
Chunling He ${ }^{1, *,+}$, Kaiyue Zhang ${ }^{1,+}$, Xiaogai Hou ${ }^{2, *}$, Dongbo Han ${ }^{1}$ and Shuaibing Wang ${ }^{1}$ \\ 1 Forestry College, Henan University of Science \& Technology, Luoyang 471000, China; \\ zhangkaiyue95@126.com (K.Z.); handongbo1994@163.com (D.H.); wsb19960820@163.com (S.W.) \\ 2 College of Agriculture, Henan University of Science \& Technology, Luoyang 471000, China \\ * Correspondence: hechunling68@sina.com (C.H.); hkdhxg@126.com (X.H.); Tel.: +86-158-9661-9818 (C.H.) \\ + Chunling He and Kaiyue Zhang contributed equally to this work.
}

Received: 20 February 2019; Accepted: 19 April 2019; Published: 25 April 2019

check for updates

\begin{abstract}
To solve the issue of insufficient pollinating of insects for the oil tree peony 'Feng Dan' (Paeonia ostii T. Hong et J.X. Zhang) and improve its seed set and yield, we conducted observations from 2017 to 2018 to investigate the relationship between honey bee (Apis mellifera L.) foraging behavior and diurnal activity. We compared the single-fruit seed set ratio among three flower types on the same plants of the oil tree peony, which flowered simultaneously, in three pollination areas (bee pollination, natural field pollination, and controlled pollination by pollinators) and in a net room under self-pollination, wind pollination and bee pollination. Apis mellifera exhibited short single visitations, long visitations to a single flower and repeated visits to flowers of the oil tree peony. The number of flower visits of $A$. mellifera was significantly and positively yet weakly correlated with the number of stigma visits (2017: $\mathrm{r}=0.045, p<0.05 ; 2018: \mathrm{r}=0.195, p<0.01)$. The seed set of oil tree peony follicles in the A. mellifera pollination area was significantly higher than that in the natural pollination field area and the control net rooms. On the same oil tree peony plant with synchronous flowering, the percent seed set of follicles pollinated by A. mellifera at a high density was significantly higher than that resulting from wind pollination and self-pollination.
\end{abstract}

Keywords: A. mellifera; oil tree peony; visitation characteristics; visitation frequency; seed set

\section{Introduction}

Peony (Paeonia suffruticosa A.) is a perennial deciduous shrub belonging to the genus Paeonia L. and the family Ranunculaceae [1]. Peony, native to China, has been cultivated for over 2000 years and was introduced to Japan, Europe and the Americas during the Tang dynasty [2]. It has desirable ornamental characteristics and medicinal value and is an ideal oil plant [3-5].

The oil tree peony is a new type of woody oil crop and an important cash crop unique to China. It has been widely planted in Shandong, Henan, Gansu, Anhui, Hubei, Chongqing, Qinghai, Tibet, and other areas in China in recent years [6]. The oil tree peony is characterized by a high seed yield, high oil content (20-35\%) and high fatty acid content (unsaturated fatty acids (UFAs) $>90 \%$ ) [7]. In particular, the $\alpha$-linolenic acid content in peony seed oil generally exceeds $40 \%$ [7,8]. Peony seed oil, in addition to being used as an edible oil, is widely utilized in cosmetics, medicine and other industries [9].

Peony is a typical insect-pollinated plant, and its main pollinators are bees (such as Andrena carbonaria, Andrena stellaria, Lasioglossum simplicior and Bombus ignitus) and beetles (such as Hybovalgus bioculatus and Cetonia magnifica) [10]. Both Paeonia delavayi F. and Paeonia decomposita F. rely on pollinators to increase their seed set $[11,12]$. The fruit set of self- and wind-pollinated 'Feng Dan' (Paeonia ostii T. Hong et J.X. Zhang) is extremely low [13]. 
Bees provide key ecological services for natural and agricultural ecosystems [14]. The total economic value of pollination services provided by bees and other insects worldwide amounted to $€ 153$ billion in 2008 [15]. The honey bee Apis mellifera L., one of the most widespread and common pollinators, can pollinate a variety of crops and boost yield [16,17]. At present, approximately $73 \%$ of the world's cultivated crops, such as cashews, squash, mangoes, cocoa, cranberries and blueberries, are pollinated by some variety of bee; $19 \%$ by flies; $6.5 \%$ by bats; $5 \%$ by wasps; $5 \%$ by beetles; $4 \%$ by birds; and $4 \%$ by butterflies and moths [14]. Pollination by bees not only improves the seed set and quality of crops such as fruit, vegetable, nut and forage crops but also greatly facilitates the fruit yield and oil yield in oil crops including beans, sunflower, rape, sesame and cotton [18-20]. The positive effect of bees on pollination is attributed to their high pollination efficiency. Bees' collection time, visitation times and pollen deposition are key factors for measuring their pollination efficiency in crops [21]. The measurement of pollinator visitation frequency can clarify the relationships between pollinators, pollinated crops and the seed set [22]. According to the literature, the visitation frequency of pollinators significantly affects the seed set of rape crops [23,24]. Oil tree peony is a superior woody oil crop; however, at present, little is known about the pollination efficiency of bees in the oil tree peony.

Therefore, we examined the foraging behaviors of A. mellifera on the oil tree peony 'Feng Dan' for two consecutive years, 2017 and 2018, mainly in terms of the time of the visit, visitation frequency, number of visits to a single flower, and diurnal activity, and their impact on the seed set of the oil tree peony. The results of this study may provide fundamental information for further exploiting the positive effects of bees on crop pollination and improving the yield of the oil tree peony.

\section{Materials and Methods}

\subsection{Sampling Location}

The experiment was conducted in an oil tree peony plantation $\left(34^{\circ} 38^{\prime} 30^{\prime \prime} \mathrm{N} ; 112^{\circ} 39^{\prime} 43^{\prime \prime} \mathrm{E} ; 125.5 \mathrm{~m}\right)$ from April 2017 to August 2018 in the East Garden of Yibin District, Luoyang city. The East Garden, located in southeastern Luoyang city and owned by Luoyang Zhenguan Peony Planting Co., Ltd., is an important part of the peony garden industrial cluster zone with an area of thousands of square hectometers in Yibin District, Luoyang. The East Garden is one of the gardens in Luoyang where the oil tree peony is grown over a large area. The oil tree peony planted in the garden is 'Feng Dan', the planting area of which exceeds $106.7 \mathrm{hm}^{2}$. 'Feng Dan' has entered the full fruit period, with a stock age of more than eight years. The primarily native bees include A. mellifera, Xylocopa appendiculata, Andrena spp., Lasioglossum spp., Anthophora sp. and Eucera sp.

\subsection{Research Materials}

In March 2017, three plots where the plants normally grew were randomly selected from the oil tree peony plantation of the East Garden in Luoyang. Two nylon net pollination houses were built in parallel in the east-west direction. Each net house was $45 \mathrm{~m}$ long from east to west and $8 \mathrm{~m}$ wide from north to south, with a 2.1-m-tall wall and a 3.2-m-high roof ridge. Each house was divided into three rooms (specifications: $15 \mathrm{~m} \times 8 \mathrm{~m}$ ), and nylon polyethylene with a mesh size of $1 \mathrm{~mm}$ was used as a screen.

As shown in Figure 1, the A, B, and C rooms were the areas with A. mellifera pollination, with one hive of honey bees (approx. 3000 worker bees, i.e., $25 / \mathrm{m}^{2}$ ) placed in each room. CK1 included the control rooms without bees, and CK2 was the field area with natural pollination. The same oil tree peony management routine was adopted in each experimental area. The A. mellifera bees were supplied by Luoyang Lilou Apiary. 


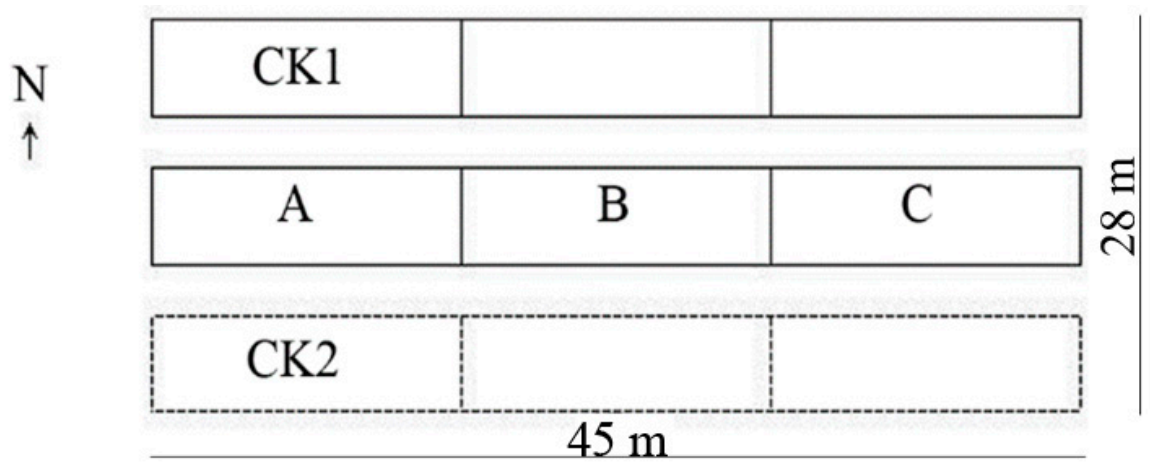

Figure 1. Plan graph of the net pollination houses built in the oil tree peony ('Feng Dan') plantation. $\mathrm{A}, \mathrm{B}$, and $\mathrm{C}$ are the A. mellifera net rooms. CK1 includes three net rooms without bees. CK2 is the field area with natural pollination.

The nets were installed before the plants flowered and removed after the bee pollination period to reduce the possible influence of the shade of the nets on the reproduction of the plants as much as possible. After the first peony flower opened in the net room, a hive of $A$. mellifera was placed in rooms A, B, and C. A beehive, $120 \mathrm{~mm}$ in height, was placed in the middle of each room. A sugar feeder (50\% sugar content) was placed in each beehive, and a drinker (filled with drinking water) was placed next to the beehive. The sugar water and drinking water were replenished and replaced regularly.

\subsection{Observation Indices}

Visual inspection, photography and videography were used to observe the foraging characteristics of $A$. mellifera on the oil tree peony. The single visitation duration, visitation interval, total visitation duration per flower, total number of visits to a single flower per foraging flight, frequency of visits to a single flower per min, and number of visits to a stigma per flower visit by A. mellifera on the oil tree peony were observed using the stopwatch matching method [25].

The measurement indicators were defined as follows:

Visitation frequency per min refers to the number of flowers that each honey bee visits per min. Single visitation duration is the time a honey bee takes to visit a flower, specifically, from the time the bee alights on the flower to the time it leaves. Visitation interval refers to the interval from the time a bee leaves a flower to the time the bee visits a flower again, including the time during which the bee temporarily leaves the flower it visits and stops mid-air to groom pollen and the time during which it flies from one flower to another. The total visitation duration per flower is the total time from the time a bee alights on a flower to the time it leaves the flower, which is the sum of the time it spends visiting a flower and the time during which it temporarily leaves the flower and grooms pollen mid-air. The total number of visits to a single flower per foraging flight refers to the total number of a bee's visits followed by pollen grooming to the same flower during one foraging flight. The stigma visitation number is the number of visits to a stigma during a bee's visit.

\subsection{Observation of Foraging Behaviors}

In 2017, we made observations for three consecutive days (15-17 April). Two $2 \mathrm{~m} \times 2 \mathrm{~m}$ sample plots were selected in each bee net room, with six plots in total. Thirty flowers in full bloom were labeled in each sample plot. Every day from 8:00 a.m. to 18:00 p.m., we recorded the number of A. mellifera visiting the flowers in each plot within 10 min every $30 \mathrm{~min}$. Similarly, we tracked and observed A. mellifera from 8:00 a.m. to 18:00 p.m. each day in each plot and recorded the visitation times and number of flowers visited by a bee in the sample plot. After a bee flew out of the sample plot, we started to track and record another bee entering the sample plot. Furthermore, the temperature, humidity and wind were recorded during different time intervals (every hour) using a hand-held meteorological instrument (Kestrel 3000; Skykomish, WA, USA). 
We made observations for three consecutive days (from 16-18 April) in 2018. Two sample plots of $2 \mathrm{~m} \times 2 \mathrm{~m}$ were set up in each bee net room, and 30 flowers were labeled in each plot. The foraging behaviors of $A$. mellifera on the flowers in each plot within 10 min every 30 min were recorded. The observation time spans were 9:30-11:45 a.m. and 13:30-14:30 p.m. (peak periods for visitation by A. mellifera, as discovered in 2017).

\subsection{Observation of Pollination Efficiency}

In the budding stage (when the buds began to soften) [26] of 'Feng Dan', 50 oil tree peony plants that bloomed simultaneously in rooms A, B and C were selected, and three buds at the same flowering stage were selected on each plant. The three buds from the same plant were pollinated with different methods: One bud was bagged with a sulfate paper bag for self-pollination; another bud was bagged with a nylon bag with a mesh size of $1 \mathrm{~mm}$ for wind and self-pollination (wind pollination); and the other bud was not bagged during blooming to allow pollination by bees within the net house (bee pollination). A total of 450 flower buds on 150 plants were labeled in three net rooms with bees as pollinators. All paper bags and screen bags were removed $15 \mathrm{~d}$ after the end of the flowering period. On 10 May 2017, three groups of green fruits pollinated with the three different methods on the same plant were picked from the three bee net rooms for statistical analysis of the seed set of the oil tree peony, with nine fruits in total. Fifteen green fruits were randomly picked from the three bee net rooms (five per room), the control rooms (CK1; five per room), and the field control area (CK2) for statistical analysis of the seed set of the oil tree peony in different pollination areas. Due to a cold spell in late spring in 2018, no data were collected for the same plants treated with different pollination methods. The seed set refers to the percentage of the number of ovules that developed into seeds in each follicle (the number of ovules ranged from 10-22, with an average of 17.24 \pm 2.44 ).

\subsection{Statistical Analysis}

Data are presented as the mean \pm standard error and were analyzed with SPSS 24.0. The Pearson correlation method was used to analyze the correlation between the numbers of single flower visits and stigma visits by $A$. mellifera on the oil tree peony. Independent-samples $t$-tests were performed to compare the flower visitation behaviors of $A$. mellifera between different years. The homogeneity of variances was tested using Levene's method, and the one-way analysis of variance (ANOVA) followed by a least significant difference (LSD) test was used for comparisons among the different treatment groups. In the case of heterogeneity, nonparametric Kruskal-Wallis one-factor ANOVA followed by a Bonferroni test was used. $p<0.05$ and $p<0.01$ were considered statistically significant and very significant, respectively.

\section{Results}

\subsection{Foraging Characteristics of A. mellifera}

When A. mellifera collects pollen, some bees fall directly onto the outer ring of the androecium and scrabble inward to collect pollen, while others scrabble on the surface of the androecium to collect pollen. Some bees directly alight on the inner ring and poke their head into the androecium (Figure 2A-D). On the same flower, bees may alight repeatedly to collect pollen several times. After collecting the pollen, bees sometimes crawl over the gynoecium or fly up and hover directly above the gynoecium to groom pollen (Figure 2E,F).

The oil tree peony is visited by $A$. mellifera from the beginning to the end of its flowering period. The visitation of the oil tree peony by $A$. mellifera is characterized by short single visits, long visits to a single flower, repeated visits to a single flower, and visitation of the same flower by several bees simultaneously (Figure 2A). A bee may alternate visits between adjacent flowers. 


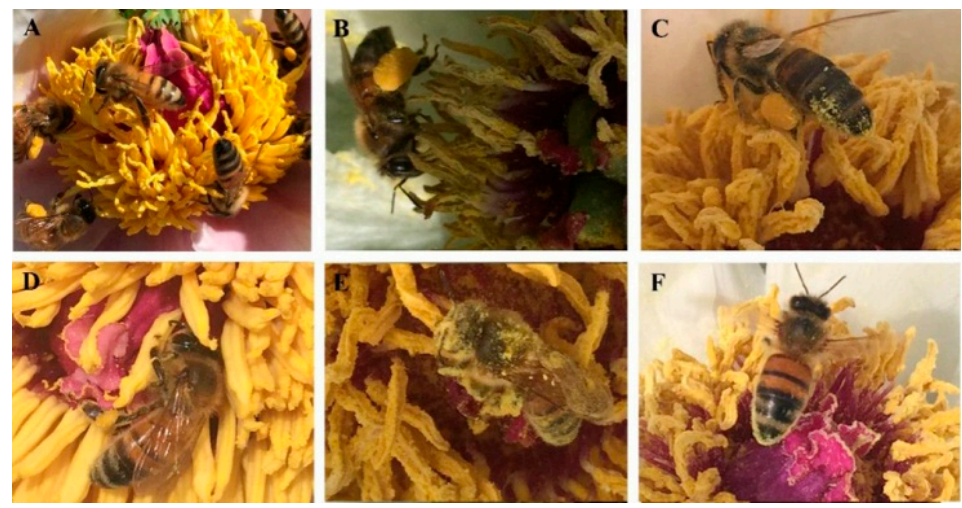

Figure 2. Foraging characteristics of A. mellifera on the oil tree peony 'Feng Dan'. (A) Multiple bees collecting pollen on the same flower; $(\mathbf{B})$ a bee collecting pollen from the outer ring of the androecium; (C) a bee crawling from the inner ring of the androecium toward the outer ring; (D) a bee collecting pollen from the inner ring of the androecium; (E) nearly the whole body of a bee contacts the stigma;

(F) a bee grooming pollen above the stigma.

\subsection{Foraging Behavior of A. mellifera on the Oil Tree Peony}

There were no significant differences in the total visitation duration per flower (independent-samples $t$-test: $\left.d f_{(1,466)}=1.102, \mathrm{t}=-1.086, p=0.294\right)$, visitation interval $\left(d f_{(1,1320)}=1.834\right.$, $\mathrm{t}=0.878, p=0.176)$, per-minute visitation frequency $\left(d f_{(1,86)}=0.613, \mathrm{t}=-0.358, p=0.436\right)$, number of visits to a single flower per foraging flight $\left(d f_{(1,394)}=2.538, \mathrm{t}=0.079, p=0.112\right)$, number of bees visiting flowers during the peak visitation period $\left(d f_{(1,50)}=1.554, \mathrm{t}=1.422, p=0.218\right)$, number of stigma visits of $A$. mellifera $\left(d f_{(1,192)}=3.206, \mathrm{t}=1.894, p=0.075\right)$, and stigma visitation ratio $\left(d f_{(1,192)}=0.538, \mathrm{t}=1.536\right.$, $p=0.468$ ) between 2017 and 2018. Although a significant difference in the single visitation duration was observed (independent-samples $t$-test: $d f_{(1,1042)}=20.282, t=-4.090, p<0.001$ ), this difference might be due to more rainfalls during the flowering season in 2018. The results are summarized in Table 1. In general, the data obtained in the two years were not significantly different; therefore, the data were pooled.

Table 1. Foraging behaviors of A. mellifera on the oil tree peony 'Feng Dan' in different years.

\begin{tabular}{ccc}
\hline Parameter & $\mathbf{2 0 1 7}$ & $\mathbf{2 0 1 8}$ \\
\hline Single visitation duration (s) & $3.48 \pm 0.11 \mathrm{~b}$ & $4.33 \pm 0.18 \mathrm{a}$ \\
Total visitation duration per flower (s) & $42.36 \pm 2.62 \mathrm{a}$ & $46.57 \pm 2.84 \mathrm{a}$ \\
Visitation interval (s) & $5.23 \pm 0.13 \mathrm{a}$ & $5.06 \pm 0.14 \mathrm{a}$ \\
Number of flowers visited per minute & $1.46 \pm 0.55 \mathrm{a}$ & $1.50 \pm 0.59 \mathrm{a}$ \\
Number of visits to a single flower per foraging flight & $5.15 \pm 0.23 \mathrm{a}$ & $5.12 \pm 0.30 \mathrm{a}$ \\
Number of bees visiting flowers & $21.23 \pm 2.17 \mathrm{a}$ & $17.08 \pm 1.33 \mathrm{a}$ \\
Number of stigma visits & $0.92 \pm 0.14 \mathrm{a}$ & $0.63 \pm 0.11 \mathrm{a}$ \\
Stigma visitation ratio $(\%)$ & $7.79 \mathrm{a}$ & $8.13 \mathrm{a}$ \\
\hline
\end{tabular}

Notes: The data in the figure are presented as the mean \pm standard error, and different letters in the same columns indicate a significant difference at $p<0.05$ (independent-samples $t$-test). Stigma visitation ratio refers to the percentage of stigma visits out of the total number of visits to a single flower.

The Pearson correlation analysis demonstrated a significant linear relationship between the number of flower visits by $A$. mellifera on the oil tree peony and the number of stigma visits because the correlation coefficient was significantly different from zero (for 2017: $\mathrm{R}^{2}=0.045, p<0.05$; for 2018: $\left.\mathrm{R}^{2}=0.195, p<0.01\right)$. 


\subsection{Activity Patterns of A. mellifera on the Oil Tree Peony}

Based on observations of the activity patterns of $A$. mellifera on the oil tree peony, when the flowers of the oil tree peony were in a half-open state between 7:00 and 8:00 in the morning, when the temperature was between $14.8-15^{\circ} \mathrm{C}$, a small number of $A$. mellifera began to fly out of the nest, while most of the bee visitation occurred after 8:30 a.m., when the temperature rose to $21-22{ }^{\circ} \mathrm{C}$. The majority of bees stopped their visitation between 17:45 and 18:00 p.m., and a few stopped their visitation after 18:00 p.m. The peak periods of the oil tree peony visitation by A. mellifera were between 9:30 and 11:45 a.m. and between 13:30 and 14:30 p.m. The temperature during the peak periods was between 28.6 and $30.3^{\circ} \mathrm{C}$ and between 29.1 and $31.6{ }^{\circ} \mathrm{C}$, respectively (Figure 3). Apis mellifera exhibited more visitation activity when the weather was fair. In the morning (before 7:00 a.m.) or in rainy and windy weather, A. mellifera rarely went out to collect pollen.

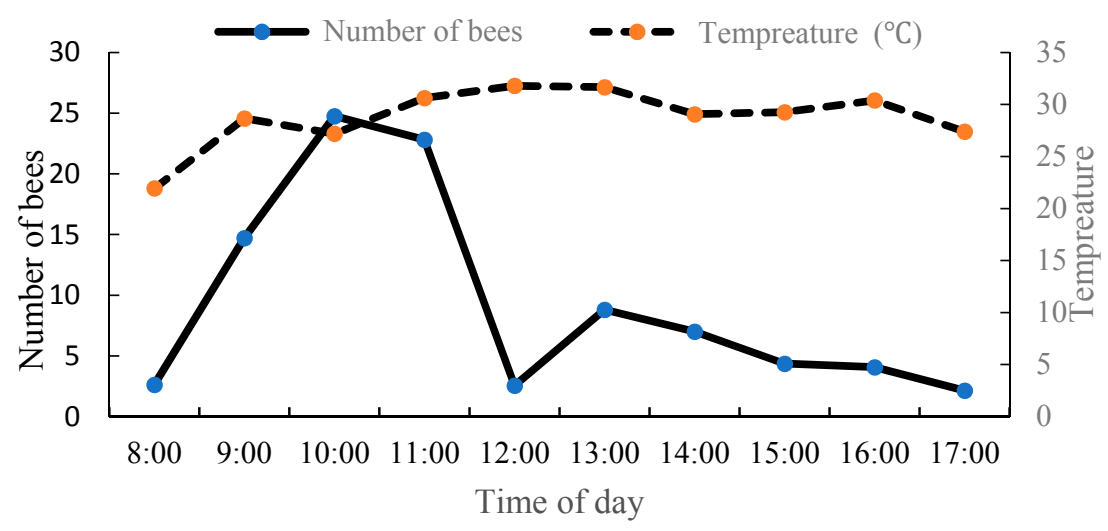

Figure 3. Diurnal activity of A. mellifera on the oil tree peony 'Feng Dan'.

Analysis of the collecting behavior of $A$. mellifera on the oil tree peony revealed that the number of peony flowers visited by $A$. mellifera (one bee) per min was between 1 and $11(n=168)$ during different periods in a day, with a mean of $2.43 \pm 0.16$. One-way ANOVA followed by an LSD test indicated significant differences among different intervals of time (Figure 4A). The total number of visits to a single flower per foraging flight was between 2 and $28(n=168)$ during different periods in a day, with a mean of $8.06 \pm 0.46$. Significant differences were also observed among different intervals of time (Figure 4B).
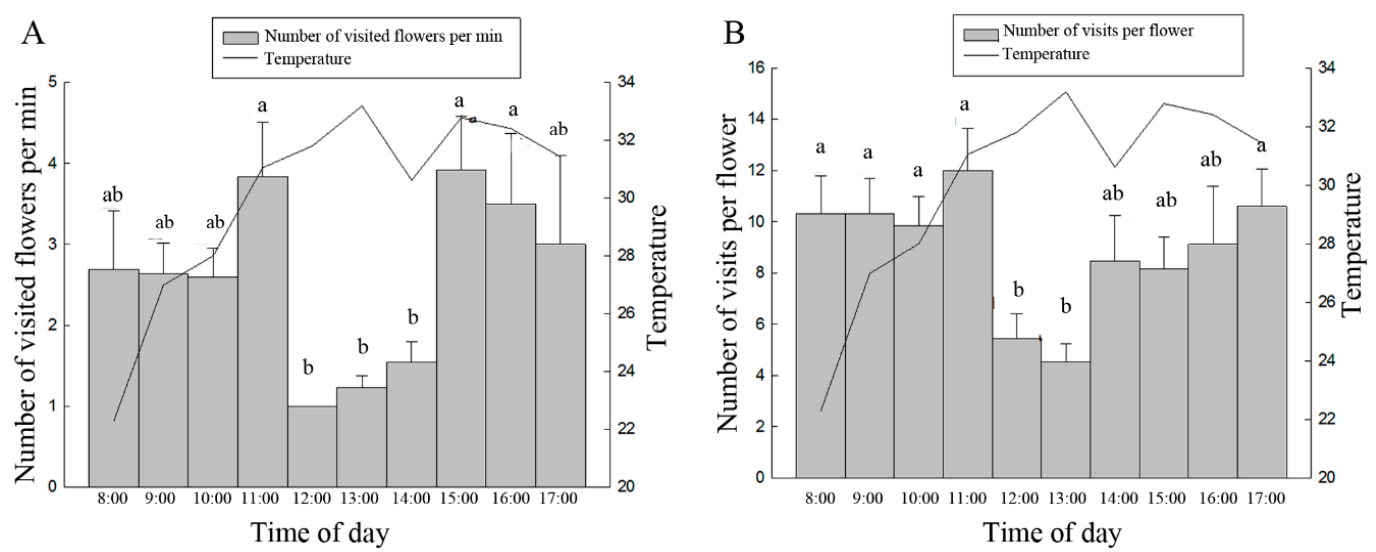

Figure 4. Collecting behavior of A. mellifera on the oil tree peony 'Feng Dan' in different time periods. (A) Number of flowers visited by A. mellifera; (B) number of $A$. mellifera visits to oil tree peony flowers. Notes: The data in the figure are presented as the mean \pm standard error, and different letters above the columns in the figure indicate a significant difference at the 5\% level (one-way ANOVA followed by an LSD test). 


\subsection{Pollination Efficiency of A. mellifera}

Analysis of the seed set of flowers on the same plant of the oil tree peony treated with different pollination methods indicated that the average seed set of the oil tree peony with A. mellifera as pollinators (open pollination) was $70.02 \% \pm 2.68 \%(n=45)$; that by wind pollination (bagged with nylon mesh bags) was $14.48 \% \pm 3.79 \%$; and that by self-pollination (bagged with sulfate paper bags) was $3.65 \% \pm 1.68 \%$. The one-way ANOVA followed by an LSD test revealed that the open-pollinated group showed a highly significant difference in the seed set rate compared with the wind-pollinated group $(p<0.001)$ and the self-pollinated group $(p<0.001)$, although a significant difference was also observed between the latter two groups $(p=0.006)$ (Figure 5).

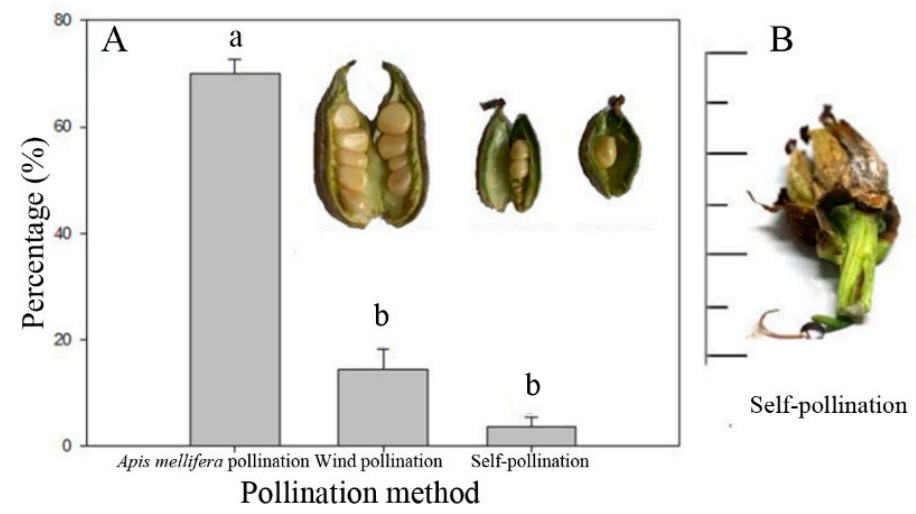

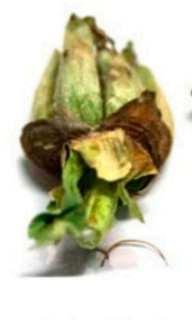

Wind pollination

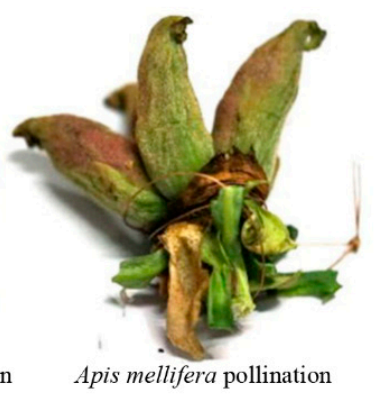

Figure 5. Seed set of the oil tree peony 'Feng Dan' treated with different pollination methods (A) and clustering follicles of the oil tree peony (B). Notes: Data in the figure are presented as the mean \pm standard error. Different letters above the columns in the figure indicate a significant difference at the $5 \%$ level (one-way ANOVA).

Analysis of the seed set of 'Feng Dan' in different pollination areas revealed that the seed set of follicles pollinated by A. mellifera was $71.16 \% \pm 2.22 \%(n=74)$, that in the control net house was $28.17 \% \pm 2.85 \%(n=76)$, and that in the field area with natural pollination was $52.16 \% \pm 2.60 \%(n=70)$. One-way ANOVA followed by an LSD test revealed that the bee group showed a highly significant difference in the seed set rate compared with the blank control group $(p<0.001)$ and the field control group $(p<0.001)$, although a significant difference was also observed between the latter two groups $(p<0.001)$ (Figure 6).

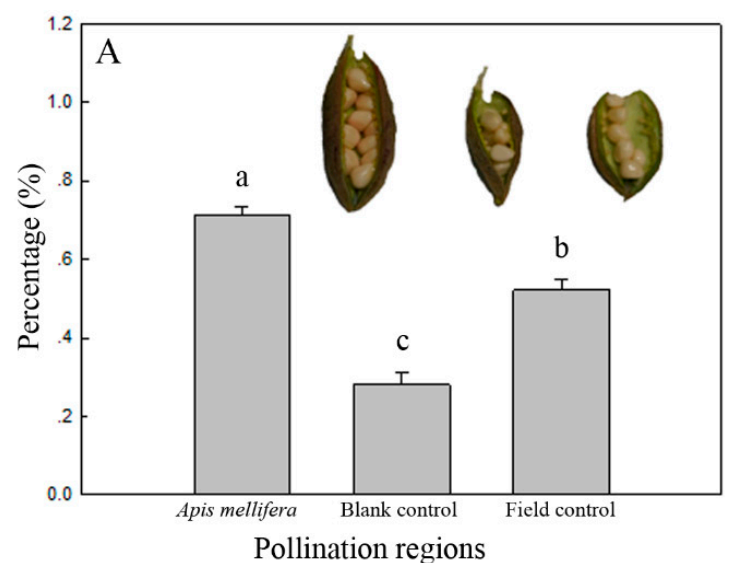

B

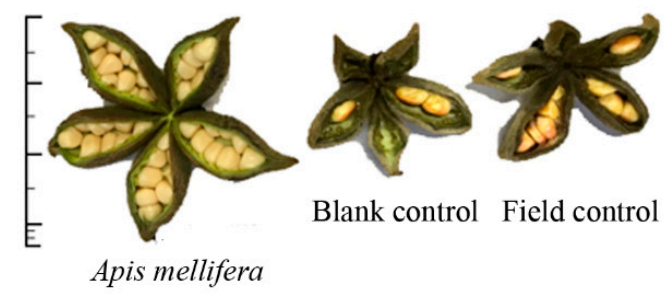

Figure 6. Seed set of the oil tree peony 'Feng Dan' in different pollination areas (A) and clustering follicles of the oil tree peony $(\mathbf{B})$. Data in the figure are presented as the mean \pm standard error. Different letters above the columns in the figure indicate a significant difference at the $5 \%$ level (one-way ANOVA). 


\section{Discussion}

At present, for pollinator-dependent flowering crops grown in large areas for commercial purposes, A. mellifera bees are important pollinators used to alleviate pollination deficits [27-29]. This experiment demonstrated that the seed set of the oil tree peony 'Feng Dan' can be effectively enhanced by increasing the number of $A$. mellifera bees.

Apis mellifera bees display different visitation characteristics and pollination efficiencies on different plants [30-33]. Bees remember their foraging areas and plants. Generally, they do not return to the flowers on which they have already foraged [34]. However, they are accustomed to foraging and pollinating plants of the same species and show stability in plant pollination [34]. This study found that $A$. mellifera bees can visit up to 10 or 11 flowers per foraging flight. The visitation to one flower by these bees was rather long, and they repeatedly visited the same flower, with a maximum of 18 visits.

The pollination efficiency of bees is closely related to their foraging behaviors and visitation duration on the pollinated plants and the number of visits; furthermore, it is also related to the amount of pollen carried by the bees and that settles on the stigma of the plant $[30,33,35,36]$. In this study, we determined indices related to the foraging behaviors of $A$. mellifera on the oil tree peony. However, the amount of pollen carried by $A$. mellifera after one foraging flight and after visits to a flower and the amount of pollen that settled on the stigma remain to be determined in the future. Furthermore, this study found that $A$. mellifera always groomed collected pollen above the stigma of the oil tree peony flower after pollen collection. The amount of pollen dropped on the stigma during collected pollen grooming also needs to be determined.

Departure from the hive by bees for collection is closely related to multiple factors such as temperature, humidity and irradiance, and the impact of temperature is far greater than that of irradiance, wind velocity and other factors [37-39]. The visitation of $A$. mellifera bees to strawberry flowers in the greenhouse begins at 9:25-9:40 a.m. (temperature $>15^{\circ} \mathrm{C}$ ), with a number of visited flowers per min of $2.38 \pm 0.15$ and a visitation interval of $6.0 \pm 0.48 \mathrm{~s}$ [31]. Their visitations to cucumber and watermelon flowers begin after 7:20 in the morning (temperature $>22{ }^{\circ} \mathrm{C}$ ), with a number of visited flowers per min of $8.0 \pm 0.2$ and $8.3 \pm 0.2$, respectively [40]. In this study, an investigation of the diurnal behaviors of $A$. mellifera on 'Feng Dan' was performed during the day on sunny days. The number of visits to a single flower and the frequency of visitation during different time intervals showed significant differences, and both showed decreased activity at noon, when the temperature was the highest. The temperature at which $A$. mellifera showed the most active visitation on the oil tree peony in this study was consistent with those reported in the literature $[30,40]$. The peak period of the oil tree peony visitation by $A$. mellifera was between 9:30 and 11:45 a.m. However, whether the pollen viability and stigma receptivity of the peony are highest during this period warrants further study.

Pollination, the process in which pollen is transferred from the anthers of the stamen to the stigma of the pistil, is critical for flowering plants. The seed set is usually used as an indicator of the success of pollination. The fruit and seed set refer to the ratio of the plant's flowers or ovules ultimately developing into fruits or seeds, respectively. Because of the natural shedding of fruit, inadequate pollination, herbivore interference or management problems, it is difficult to achieve $100 \%$ fruit or seed set [41]. For crops that rely on pollinators for pollination, pollination efficiency is directly affected by the abundance of pollinators [42,43]. 'Feng Dan', characterized by a high seed yield and seed oil content and good oil quality, is the main cultivar used in China's oil tree peony industry; however, it is a cross-pollinated plant with a low (potentially zero) self-pollination seed set [13,44]. From 2017 to 2018, the seed set of 'Feng Dan' pollinated by A. mellifera was significantly higher than that in the control net house and field area with natural pollination. In this study, we set up a net pollination house to increase the pollination of 'Feng Dan' by western honeybees. The results of our study show that the seed set of 'Feng Dan' is significantly improved by bee pollination and that A. mellifera is an effective pollinator of the oil tree peony 'Feng Dan'; however, the impact of pollination on the yield and quality of peony seeds requires further study. 


\section{Conclusions}

The seed set of oil tree peony follicles can be significantly increased by A. mellifera. The results of our research indicate that $A$. mellifera is an effective pollinator of the oil tree peony and thus can greatly boost its yield.

However, this study may suffer from the limitation of a small sample size. To further validate the findings of this study, studies based on a larger sample size remain to be conducted. In addition, the findings of this study were obtained with net houses. The pollination effect of $A$. mellifera in the field environment and the optimal density of bees in the field environment need to be explored.

Author Contributions: Conceptualization, K.Z. and C.H.; Methodology, C.H.; Software, X.H.; validation, X.H. and D.H.; Formal analysis, S.W.; Investigation, D.H. and S.W.; Resources, C.H.; Data curation, X.H.; Writing-original draft preparation, K.Z.; Writing-review and editing, C.H.; Visualization, X.H.; Supervision, X.H.; Project administration, C.H.; Funding acquisition, C.H.

Funding: This research was funded by the National Natural Science Foundation of China, grant numbers U180423 and U1304308, and the Henan Science and Technology Program, grant number 162102110101.

Acknowledgments: We would like to express our gratitude to An Jiandong, research fellow at the Institute of Agricultural Research, Chinese Academy of Agricultural Sciences, and Zhang Hong for their guidance and suggestions on the experimental design and to Yang Dongshuo of Luoyang Normal University for his help during the field experiment. Our thanks also go to the research base of Luoyang Zhenguan Peony Planting Co., Ltd.

Conflicts of Interest: The authors declare no conflict of interest. The funders had no role in the design of the study; in the collection, analyses, or interpretation of data; in the writing of the manuscript; or in the decision to publish the results.

\section{References}

1. Hong, D.Y.; Pan, K.Y. Taxonomical history and revision of Paeonia Sect. Moutan (Paeoniaceae). J. Syst. Evol. 1999, 37, 351.

2. Cheng, F.Y.; Li, J.J. Exportation of Chinese tree peonies (Mudan) and their development in other countries II: Cultivated. J. Northwest Norm. Univ. (Nat. Sci.) 1998, 3, 106-111.

3. Picerno, P.; Mencherini, T.; Sansone, F.; Del Gaudio, P.; Granata, I.; Porta, A.; Aquino, R.P. Screening of a polar extract of Paeonia rockii: Composition and antioxidant and antifungal activities. J. Ethnopharmacol. 2011, 138, 705-712. [CrossRef] [PubMed]

4. Li, S.S.; Chen, L.G.; Xu, Y.J.; Wang, L.J.; Wang, L.S. Identification of floral fragrances in tree peony cultivars by gas chromatography mass spectrometry. Sci. Horticul. 2012, 142, 158-165. [CrossRef]

5. Peng, L.P.; Cai, C.F.; Zhong, Y.; Xu, X.X.; Xian, H.L.; Cheng, F.Y.; Mao, J.F. Genetic analyses reveal independent domestication origins of the emerging oil crop Paeonia ostii, a tree peony with a long-term cultivation history. Sci. Rep. 2017, 7, 5340. [CrossRef]

6. Liu, D.J.; Jiao, X.X. Development status and countermeasures of oil tree peony industry. West. For. Sci. 2015, $44,170-173$.

7. Qi, J.C.; Zhou, H.M.; Ma, J.Q.; Li, P. Analysis of the chemical constituents in peony seed oil by GC-MS. Cereals Oils 2005, 11, 23-24.

8. $\quad$ Li, S.S.; Yuan, R.Y.; Chen, L.G.; Wang, L.S.; Hao, X.H.; Wang, L.J.; Zheng, C.X.; Du, H. Systematic qualitative and quantitative assessment of fatty acids in the seeds of 60 tree peony (Paeonia section Moutan DC.) cultivars by GC-MS. Food Chem. 2015, 173, 133-140. [CrossRef]

9. Shi, G.A.; Jiao, F.X.; Jiao, Y.P.; Yang, H.A.; Han, M.W.; Wu, Y.Q.; Shi, B.R. The development prospect and countermeasures of Chinese oil peony. Cereals Oils Assoc. 2014, 29, 124-127.

10. Luo, Y.B.; Pei, Y.L.; Pan, K.Y.; Hong, D.Y. A study on pollination biology of Paeonia suffruticosa A. var. spontanea R. Acta Phytotaxonomica Sinica 1998, 36, 134-144.

11. Li, K.; Zheng, B.Q.; Wang, Y.; Guo, X. Flowering characteristics and breeding system of Paeonia delavayi. J. Northeast For. Uni. 2013, 41, 63-67.

12. Yang, Y.; Luo, J.T.; Zhang, B.F.; Song, H.X.; Liu, G.L.; Zeng, X.L. Studies on floral characteristics and breeding system of Paeonia szechuanica F. J. Plant Resour. Environ. 2015, 24, 97-104. 
13. Han, X.; Cheng, F.Y.; Xiao, J.J.; Wang, Y.L.; Zhang, D.; Wang, Y.; Zhong, Y. Crosses of Paeonia ostii T.Hong et J.X.Zhang as maternal parents and an analysis on the potential in tree peony breeding. J. Beijing For. Univ. 2014, 4, 121-125.

14. Abrol, D.P. The role of pollination in improving food security and livelihoods. Pollination Biol. 2011, 2011, 737-770.

15. Gallai, N.; Salles, J.M.; Settele, J.; Vaissiere, B.E. Economic valuation of the vulnerability of world agriculture confronted with pollinator decline. Ecol. Econ. 2009, 68, 810-821. [CrossRef]

16. Cunningham, S.A.; Fitz Gibbon, F.; Heard, T.A. The future of pollinators for Australian agriculture. Aust. J. Agric. Res. 2002, 53, 893-900. [CrossRef]

17. Rucker, R.R.; Thurman, W.N.; Burgett, M. Honey bee pollination markets and the internalization of reciprocal benefits. Am. J. Agric. Econ. 2012, 94, 956-977. [CrossRef]

18. Klein, A.M.; Vaissière, B.E.; Cane, J.H.; Steffan-Dewenter, I.; Cunningham, S.A.; Teja Tscharntke, C.K. Importance of pollionators in changing landscapes for world crops. Proc. R. Soc. B Biol. Sci. 2007, 274, 303-313. [CrossRef]

19. Abrol, D.P.; Shankar, U. Pollination in oil crops: Recent advance sand future strategies. In Technological Innovations in Major World Oil Crops; Gupta, S.K., Ed.; Springer Science + Business Media: Berlin, Germany, 2012; Volume 2, pp. 221-265.

20. Bommarco, R.; Marini, L.; Vaissière, B.E. Insect pollination enhances seed yield, quality, and market value in oilseed rape. Oecologia 2012, 169, 1025-1032. [CrossRef]

21. Fishbein, M.; Venable, D.L. Diversity and temporal change in the effective pollination of Asclepias tuberosa. Ecology 1996, 77, 1061-1073. [CrossRef]

22. Thomson, J.D.; Mcjenna, M.A.; Cruzan, M.B. Temporal patterns of nectar and pollen production in Aralia hispida: Implications for reproductive success. Ecology 1989, 70, 1061-1068. [CrossRef]

23. Morandin, L.A.; Winston, M.L. Wild bee abundance and seed production in conventional, organic, and genetically modified canola. Ecol. Appl. 2005, 15, 871-881. [CrossRef]

24. Jauker, F.; Bondarenko, B.; Becker, H.C.; Steffan-Dewenter, I. Pollination efficiency of wild bees and hoverflies provided to oilseed rape. Agric. Forest Entomol. 2012, 14, 81-87. [CrossRef]

25. He, C.L.; Li, X.P.; Zhang, H.X. Food plants and foraging behaviors of Xylocopa appendiculata (Hymenoptera, Apidae) in Luoyang, Henan Province, central China. Entomologica Sinica 2012, 55, 444-456.

26. Li, J.Y.; Zhang, X.F.; Zhao, X.Q. The Peony of China; Encyclopedia of China Publishing House: Beijing, China, 2011; Volume 3, pp. 30-50.

27. Delaplane, K.S.; Mayer, D.E. Crop Pollination by Bees; CABI Publishing: Wallingford, CT, USA, 2000; pp. 1-20.

28. Deguines, N.; Jono, C.; Baude, M.; Henry, M.; Julliard, R.; Fontaine, C. Large-scale trade-off between agricultural intensification and crop pollination services. Front. Ecol. Environ. 2014, 12, 212-217. [CrossRef]

29. Blaauw, B.R.; Isaacs, R. Flower plantings increase wild bee abundance and the pollination services provided to a pollination dependent crop. J. Appl. Ecol. 2014, 51, 890-898. [CrossRef]

30. Gonzalez, V.H.; Mantilla, B.; Palacios, E. Foraging activity of the solitary andean bee, Anthophora walteri (Hymenoptera: Apidae, Anthophorini). Revista Colombiana de Entomologia 2006, 32, 73-76.

31. Li, J.L.; Peng, W.J.; Wu, J.; An, J.D.; Guo, Z.B.; Tong, Y.M.; Hang, J.X. Comparison of pollination behavior of Bombus lucorum and Apis mellifera for pollinating strawberry in greenhouse. Acta Entomologica Sinica 2006, 2, 342-348.

32. An, J.D.; Wu, J.; Peng, W.J.; Tong, Y.M.; Guo, Z.B.; Li, J.L. Foraging behavior and pollination ecology of Bombus lucorum L. and Apis mellifera L. in greenhouse peach garden. J. Appl. Ecol. 2007, 5, 1073-1078.

33. Mensah, B.A.; Kudom, A.A. Foraging dynamics and pollination efficiency of Apis mellifera and Xylocopa olivacea on Luffa aegyptiaca Mill (Cucurnitaceae) in southern Ghana. J. Pollination Ecol. 2011, 4, 34-38.

34. Qin, J.D. The Relationship between Insects and Plants; Science Press: Beijing, China, 1987; pp. 188-204.

35. Bosch, J.; Blas, M. Foraging behavior and pollinating efficiency of Osmia cornuat and Apis mellifera on almond (Hymenoptera, Megachilidae and Apidae). Appl. Entomol. Zool. 1994, 29, 1-9. [CrossRef]

36. Thomson, J.D.; Goodell, K. Pollen removal and deposition by honeybee and bumblebee visitors to apple and almond flowers. J. Appl. Ecol. 2001, 38, 1032-1044. [CrossRef]

37. Chen, S.L. The Apicultural Science in China; China Agricultural Press: Beijing, China, 2001; pp. $178-196$.

38. Bluthgen, N.; Klein, A.M. Functional complementarity and specialisation: The role of biodiversity in plant pollinator interactions. Basic Appl. Ecol. 2011, 12, 282-291. [CrossRef] 
39. Lee, K.Y.; Yim, S.H.; Kim, S.Y.; Yoon, H.J. Comparison of pollination activities between honeybee (Apis mellifera L.) and bumblebee (Bombus terrestris L.) during the flowering period of Asian pear (Pyrus pyrifolia N.) under variable weather conditions. J. Apicult. 2016, 31, 247. [CrossRef]

40. Stanghellini, M.S.; Ambrose, J.T.; Schultheis, J.R. Diurnal activity, floral visitation and pollen deposition by honey bees and bumble bees on field-grown cucumber and watermelon. J. Apicult. Res. 2002, 41, 27-34. [CrossRef]

41. Delaplane, K.S.; Dag, A.; Danka, R.G.; Freitas, B.M.; Garibaldi, L.A.; Goodwin, R.M.; Hormaza, J.I. Standard methods for pollination research with Apis mellifera. J. Apicult. Res. 2013, 52,1-28. [CrossRef]

42. Sabbahi, R.; Oliveira, D.; Marceau, J. Influence of honey bee (Hymenoptera: Apidae) density on the production of canola (Crucifera: Brassicacae). J. Econ. Entomol. 2005, 98, 367-372. [CrossRef]

43. Peña, J.F.; Carabalí, A. Effect of honey bee (Apis mellifera L.) density on pollination and fruit set of avocado (Persea americana MILL.) cv. HASS. J. Apicult. Sci. 2018, 62, 5-14. [CrossRef]

44. Si, B.; Zhang, Y.L.; Niu, L.X.; Wen, K.X.; Luo, J.R.; Xie, L.X. Selection research on pollination cultivar for Paeonia ostii T. Hong et J.X. Zhang in oil cultivation system. North. Horticult. 2016, 20, 58-61.

(C) 2019 by the authors. Licensee MDPI, Basel, Switzerland. This article is an open access article distributed under the terms and conditions of the Creative Commons Attribution (CC BY) license (http://creativecommons.org/licenses/by/4.0/). 